evolved was still greater and the color of the mixture almost black. Anhydrous sodium carbonate had the same effect, though in a lesser degree. Again, when the cyanide and the plaster had both been carefully dried the air was drawn over them for four days and no hydrocyanic test could be gotten in the final tube of potassium hydroxide.

The mixture of potassium cyanide and anhydrous calcium sulphate left after two or three days of aspirating was examined and found to contain potassium hydroxide. The reaction then is probably

$$
\mathrm{KCN}+\mathrm{H}_{2} \mathrm{O}=\mathrm{HCN}+\mathrm{KOH} \text {. }
$$

It has been shown by Karsted (Poggendorff's Annalen, 115,348) and Storer (Amer. Chem. Journal v. 69) that where air alone comes in contact with corks and organic connectors carbon dioxide is formed. This would probably account for decomposition when potassium cyanide and water alone were used, but the greatly increased depth of test when plaster of Paris is added shows a decided action on the part of that body.

Chemical Laboratory, University of N. C.

\title{
RATE OF REVERSION IN SUPERPHOSPHATES PRE- PARED FROM RED NAVASSA ROCK.
}

$$
\text { By W. B. Phillifs, Ph. D. }
$$

The manufacture of a high grade superphosphate from Red Navassa rock is one of those problems which, appearing easy of answer, yet present great difficulties. How great these difficulties are, only the manufacturer knows. Working formulæ which on other natural phosphates give entire satisfaction, on red Navassa give curious and rather discouraging results. In this rock we have to deal with a mixture of the phosphates of calcium, iron, and aluminium, and the oxides of iron, and aluminium. The superphosphate made from it is consequently of a more complicated structure than that made almost entirely of tri-calcium phosphate, i. e., from bone, or Apatite, or Charleston Rock.

In the superphosplate itself, the rapidity with which reversion takes place is largely dependent upon the content of iron and 
aluminium. In most cases, if all the phosphoric acid has been rendered soluble, the reversion proceeds slowly. But if any unattacked iron and aluminium oxides are present, the reversion proceeds rapidly. (Compare H. Joulie, Compt. Rendus 88, 1879, p. 1324, and Carl Ferd. Meyer, Zeit. An. Chem. 1880, p. 309.)

I have recorded in the following tables the results of some observations made on superphosphates prepared from red Navassa rock. The material used was of uniform fineness, the whole of it passing through a 60 mesh sieve. The samples were prepared so that in one there should be about 5 per cent., in another about 8 per cent., and in the third about 14 per cent. soluble phosphoric acid.

The same method of analysis was used in every case. All the phosphoric acid determinations were made with ammonium molybdate. For the estimation of insoluble phosphoric acid there was used a slightly alkaline solution of ammonium citrate, $100 \mathrm{c.}$ c. to 2 grms., time 30 mins. Some of the comparative determinations of insoluble phosphoric acid had to be omitted from lack of time, but it is hoped that those that appear will prove to be sufticient for the end in view. The reverted phosphoric acid was determined by difference.

TABLE I.

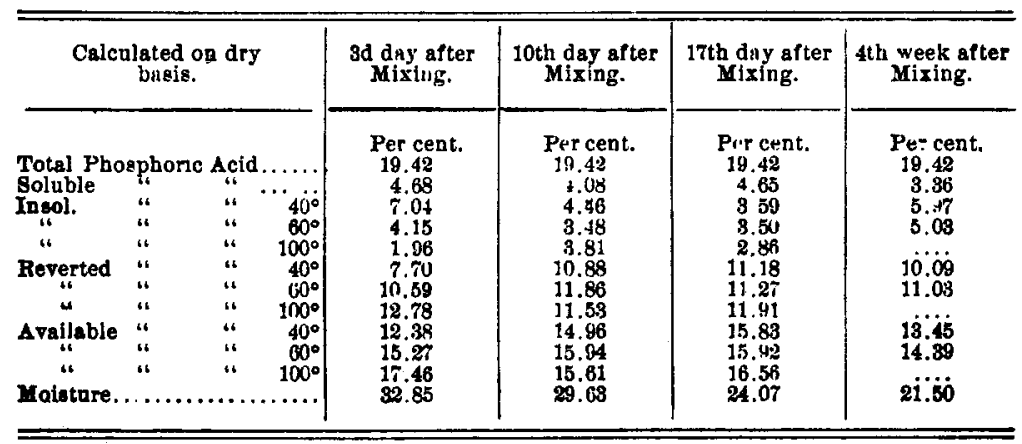


TABLE II.

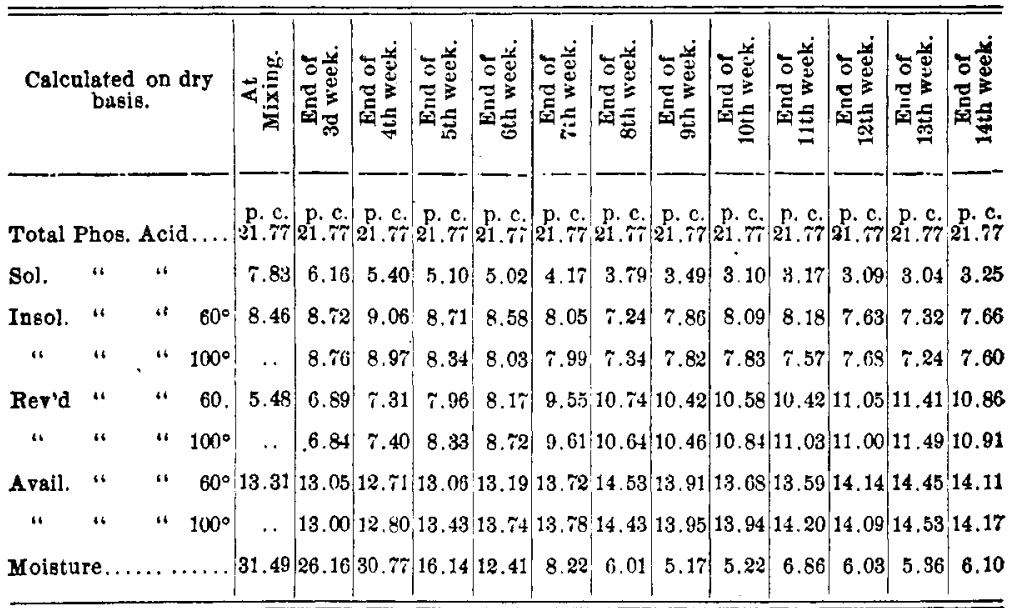

TABLE III.

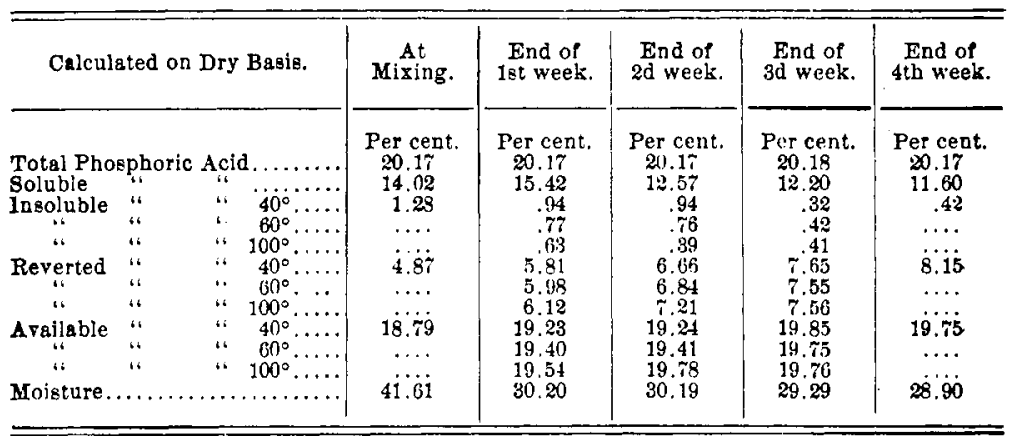

The sample yielding about 8 per cent. soluble phosphoric acid was examined through a much longer time than either of the others. For comparison, therefore, we must consider them at the end of the same time, i. e., at the end of the fourth week. During this time, as indeed throughout the experiment, the samples worked on stood in large earthen ware pans in the laboratory and were protected from dust. 
Table IV. shows the rate of reversion for 4 weeks, absolute and comparative, and the accompanying loss of moisture :

TABLE IV.

\begin{tabular}{|c|c|c|c|c|c|c|c|c|}
\hline \multirow[b]{2}{*}{ Soluble } & \multirow{2}{*}{\multicolumn{2}{|c|}{ PLosphoric Acid. }} & \multirow{2}{*}{$\begin{array}{c}\text { At } \\
\text { Mixing. } \\
\\
\text { Per cent. } \\
4.68\end{array}$} & \multicolumn{2}{|c|}{$\begin{array}{l}4 \text { weeks. } \\
\text { after Soss of } \\
\text { Mixing. Soluble. }\end{array}$} & $\begin{array}{l}\text { Reverted } \\
\text { p.c. of } \\
\text { Original } \\
\text { Soluble. }\end{array}$ & \multirow{2}{*}{$\begin{array}{c}\text { Loss of } \\
\text { Moisture } \\
\text { in } 4 \\
\text { Weeks. } \\
\text { Per cent. } \\
11.35\end{array}$} & \multirow{2}{*}{$\begin{array}{c}\text { Loss of } \\
\text { Moisture } \\
\text { p. c of } \\
\text { Original. } \\
\text { Per cent. } \\
34.55\end{array}$} \\
\hline & & & & $\begin{array}{c}\text { Per cent. } \\
3.36\end{array}$ & $\begin{array}{c}\text { Per cent. } \\
1.32\end{array}$ & $\begin{array}{c}\text { Per cent. } \\
\mathbf{2 8 . 2 1}\end{array}$ & & \\
\hline$"$ & " & $"$ " & 7.83 & 5.40 & 2.43 & 31.03 & 10.72 & 34.05 \\
\hline “ & " & “ & 14.02 & 11.60 & 2.42 & 17.26 & 12.75 & 30.61 \\
\hline
\end{tabular}

TABLE V-COMPARE TABLE II.

Behayior of Insol. Phos. Acid.

\begin{tabular}{|c|c|c|c|c|c|c|c|c|c|c|c|}
\hline \multicolumn{4}{|c|}{ + denotes gaiu. } & \multicolumn{4}{|c|}{ - denotes loss. } & \multicolumn{4}{|c|}{ End of Weeks. } \\
\hline 3 & 4 & 5 & 6 & $\tau$ & 8 & 9 & 10 & 11 & 12 & 13 & 14 \\
\hline$+p_{.26}$ & $+\underset{.60}{\text { p. }}$ c. & + p. c. & ${ }^{+} .12$ & $-p_{.4} c$ & $-p_{1.22} c$ & $-p_{60} c$ & - p.c. & $-p_{.28} c$ & $-\mathrm{p}_{\mathrm{83}} \mathrm{c}$ & ${ }_{1.14}^{\mathrm{p} . \mathrm{c}}$ & $-p_{.8} c$ \\
\hline
\end{tabular}

TABLE YI-COMPARE TABLE II.

Begatior of Soluble and Reverted Phos. Acid, 60\%,

\begin{tabular}{|c|c|c|c|c|c|c|c|c|c|c|c|c|}
\hline & 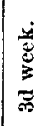 & 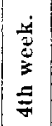 & $\begin{array}{l}\frac{y}{0} \\
0 \\
5 \\
\frac{5}{25}\end{array}$ & 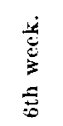 & 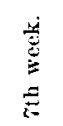 & 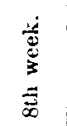 & 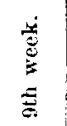 & 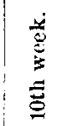 & 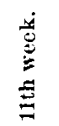 & 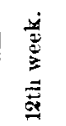 & 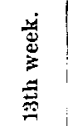 & 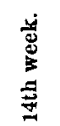 \\
\hline Loss of Phos.|Acid & p.c. & p.c. & $\begin{array}{l}\text { p.c. } \\
2.73\end{array}$ & $\begin{array}{l}\text { p.c. } \\
2.81\end{array}$ & $\begin{array}{l}\text { p.c. } \\
3.66\end{array}$ & $\begin{array}{l}\text { p.c. } \\
4.04\end{array}$ & $\begin{array}{l}\text { p.c. } \\
4.34\end{array}$ & $\begin{array}{l}\text { p.c. } \\
4.73\end{array}$ & $\begin{array}{l}\text { p. c. } \\
4.66\end{array}$ & $\begin{array}{l}\text { p.c. } \\
4.74\end{array}$ & $\begin{array}{l}\text { p.c. } \\
4.79\end{array}$ & $\begin{array}{l}\text { p. c. } \\
4.58\end{array}$ \\
\hline Gain Revt'd & 1.41 & 1.83 & 2.48 & 2.69 & 4.07 & 5.26 & 4.94 & 5.10 & 4.94 & 5.57 & 5.93 & 5.38 \\
\hline
\end{tabular}

The most striking fact brought out by these tables is that the insoluble phosphoric acid is not stationary, but oscillates from week to week. Thus from Table V. it is seen that this oscillation of insoluble phosphoric acid is from a gain of .60 per cent. to a loss 1.22 per cent., the interval between being four weeks.

The oscillation of insoluble phosphoric acid has been touched upon by J. Post, (Chem. Industr. 1882, p. 217), who states, among otber most interesting facts, this, that during the first month the 
phosphates which have become insoluble in water remain soluble in citrate at $40^{\circ}$; but later on a part of the reverted phosphoric acid insoluble at $40^{\circ}$ becomes insoluble in citrate even at $90^{\circ}$. In other words, the per cent. of insoluble phosphoric acid varies from time to time. In reflecting upon this subject, there was reason to suspect that this variation was largely controlled by the mechanical condition of the analytical sample. Some experiments were begun on this point, but could not be carried through, owing to the pressure of routine work. In passing an article of 6 per cent. or 8 per cent. moisture through a 40 mesh sieve, a good deal of it must necessarily be pulverized finer than the sieve. The less moisture the article holds, other things being equal, the more will there be of it much finer than the seive. The citrate acts upon this fine stuff more effectually than upon the coarser, and in this way the variation of the insoluble phosphoric acid may be partially explained. Doubtless this has some effect, for from the 7th through the 14th week, Tables II. and V., when the moisture varied from 8.22 per cent. to 5.17 per cent., there was a loss of insoluble phosphoric acid all the time.

Other interesting points might well be considered did this space allow. Such as they are the careful reader will recognize. It is hoped to follow up this discussion with some parallel observations as soon as possible.

Laboratory of the Narassa Guano Company,
Wilmington, N. C. 